\title{
THE EFFECT OF NATURE ON SOCIAL INTERACTIONS IN URBAN SQUARES
} (CASE STUDY: SQUARES OF TEHRAN)

\author{
H. R. Saremi ${ }^{1, *}$, Z. Ghasemi ${ }^{2}$, M. R. Bemanian ${ }^{3}$, M. Sattarpour ${ }^{2}$ \\ ${ }^{1}$ Assistant Professor, Department of urbanism, Faculty of Art and Architecture, Tarbiat \\ Modares University, Tehran, Iran \\ ${ }^{2}$ Department of Architecture, College of Architecture, Boroujerd Branch, Islamic Azad \\ University, Boroujerd, Iran \\ ${ }^{3}$ Department of Architecture, Faculty of Art and Architecture, Tarbiat Modares University, \\ Tehran, Iran
}

Published online: 16 July 2016

\begin{abstract}
One of the issues that have been considered in the urban space is improving the quality of these spaces. Using nature and its elements can play a role in promoting them and this role can be sought in the relationship between man, nature and identification of nature's effect on artificial environment and their interactions with each other. Because of the importance of urban environments and squares as one of the most important of these spaces and their role in the development of society, the focus is on squares the effect of nature on social interactions and the way nature responds to some psychological needs of human is assessed. In this study, using descriptive analytical design and through library research method, it was proved that vitality and sociability in urban areas, have a significant impact on increasing social interaction and increase of these factors improve urban spaces.
\end{abstract}

Author Correspondence, e-mail: saremi@ modares.ac.ir doi: http://dx.doi.org/10.4314/jfas.v8i2s.118 
Using correlation method, questionnaires and analysis of them using SPSS, it was concluded that the use of natural space with the appropriate design, has a significant impact on satisfaction, sociability, creating vitality and local identity and ultimately increase of social interactions.

Key words: urban space, square, natural space, vitality, sociability, social interactions.

\section{INTRODUCTION}

The formation of human behavior in environment is the outcome of stimulations, individual needs, environmental features and perception of human. In the meantime, urban space has become a place to explore, meet of the people and lack of attention to it causes cognitive crisis and conflict of behavioral patterns with functional content of space.

Cities have spaces that are considered as expression of culture, technology and civilization in a society. Urban spaces reflect a society that particularly affects people of that society and have mutual interaction with them.Identity reflects the features of any person or phenomenon (Bemanian, et al., 2010, 40). Public spaces and the face of a city can reveal the identity of the inhabitants of that city. Also it affects social, cultural, artistic and economic relationships of a society and takes special form in any place. These spaces are open spaces that can be the scene of social life in city in which many events occurs. Urban space can facilitate social relations, social structure refinement, and processof sociability and field of applying social norms and in other words it is the stage of life display (Parsi, 2002, 41).

Concepts such as happiness and sociability, liveliness things that have been proposed in this paper based on the research on increasing social interaction in urban squares play. This article is an effort to show the importance of designing natural space in urban spaces such as square andto increase vitality and enhance the quality of these spaces and investigate influenceof the nature on various factors. Concepts such as happiness and sociability and liveliness are things that have been proposed in this paper that play a role in increasing social interaction in urban squares based on the studies performed.

\section{RESEARCH METHODOLOGY}

In this study, first relationship between satisfaction and sociability and vitality in the growth of social interactions was assessed using descriptive analytical design, through library method and use of existing documents and then the relationship between presence of natural space and increased satisfaction and sociability and vitality was measured through correlational research method using questionnaire and data analysis by SPSS software. The 
statisticalpopulation of this study included 6 Square in Tehran that is completed byspecialists' questionnaire.

\section{Research background}

Given the importance of the natural space and urban spaces, several studies have been conducted on these two issues separately. Among these, theorists such as Rappaport (1977) can be mentioned whoproposed issue of interaction between humans and the environment posed in urban planning and designing. And also theories and city and square guide books by Paul Zucker (1959), view of city by Kevin Lynch (1960), city perspective by Gordon Cullen (1961), urban space of Rob Carrier (1975), creation of architectural theory (the role of behavioral Sciences in environmental design) by John Lang (1987), analysis of urban spaces in relation to the behavior patterns of users by Hossein Bahraini ( 1996), urban design: streets and squares by Cliff Matyn (1999), design of urban spaces by Ali Madani Poor (2000), and urban space design in iran by Jahanshah Pakzad (2005) can be pointed out that generally and specifically explored these relationships in public spaces of neighborhoods and cities. There are also numerous articleson the area of natural space and its role in the urban space and different styles have been created in line with the friendship between artificial environment and nature.It should be noted that there has been little research on the relationship between natural environment and square as one of the most important urban spaces. As a result, this study can play an important role in increasing quality and creating squareswith special attention to the natural environment.

\section{4-Square}

Human life has social nature that is not obtained exceptby division of responsibilities and tasks in accordance with the laws, traditions and systems.Public space is"coexistence spaceand aplace for presentation of role and test of reality and exploration of difference andidentity andan area for being accepted by others" (Madanipur, 2008, 266). Through power of thinking, human has come to the conclusion that he will have a better life and benefit more endowments of creation through partnership and cooperation;thus public people think participation is a natural desire and rational agreement. Squares are suitable place for presence of citizens and their participation and interaction in public life and has caused they understand interactional relationships and togethernessbetter. This has improved promotionof individual members of society and the whole society.

\subsection{Social Interactions}

If the person does an act that is associated with the response from the other person, it is called mutual interaction, social interaction or mutual social action. In this case, a social relation is 
established between these two people (Fielding Agbern and Half Kuf, 13). Human needs are generally divided into two material and spiritual, natural needs that social interactions can be named as one of man's natural needs. Thus, social interactions and relations are both named a natural need and the means to satisfy other needs, so that man human being is not able to live without establishing social relationships (Rafipour, 2003). Type, quality and socialityof urban spaces can be important in forming of productive social interactions or shaping citizen participation or forming and organizing social capital in urban structure , (PourMohammadi, Kushaneh, 2013, 44). Vitality causes increased space quality and is considered as one of important factors in social interactions.Also sociability affects formation and permanence of socialinteractions and thus improves the quality of knowledge and experience of users.

Individuals form their lives through social skills from birth time, these skills have profound impact on human capabilities and activities (playing, working, learning, filling leisure time), (Aksoy, Baran , 2010,663).

Vygotsky considers social skills as determinant of cognitive development, so social environment should be strengthened to improve cognitive development of humans who are being grown in that environment. In his opinion, knowledge and attitudes and values of a personare evolved in the process of interaction with others (Seif, 2007, 220). Squares of a cityare as a context for the continuous presence of people at different times of day that social interactions and relationships are one ofits characteristics.

\section{4-1-1Sociability:}

Social spaces and consequently sociability includes different individuals and social groups that exchange ideas and information as well as sharing them with each other. Such spacesare experience rather than justspace (Hajer, Reijndorp, 2001, 11). According to the definition by Humphrey Esmund, using the words "Sociopetal Spaces " or "social-friend spaces," "gathering and sociability spaces " or "scattering spaces" represent the qualities of spaces that gather people together, or apartthem (Smond, 1957, 26).Sociability spaces have provided an opportunity for the users of the space toestablish own social dialogues and social interactions occureasily in such an environment.

\section{4-1-2 Vitality:}

Vital urban space is an urban space where the presence of a significant number of people and their diversity (In terms of age and gender) is seen in a wide range of day time when their activities occur mainly in the form of social or selective, (Khesto, Saeedi Rezvani, 2010, 64). (Confessor, Saeed Rezvani, 2010, 64). The role of urban space, i.e. space where social 
interaction of citizens is formed and society culture is promoted inits context, is declining day by day in our country. Its cities and neighborhoods act like a living organism and need vitality to survive. Life of individual means being amongst population, and what gives life to a space is people and their active and vital presence in space (Pakzad, 2003, 98). This presence that is appropriate background to establish social interactions can become moreactive and majestic and sense of belonging increase in that space with vitality . Clearly, presence of people is necessary for vitality of urban spaces, (Khesto, Saeed Rezvani, 2010, 64). To achieve a vital city or vitality in urban life, places and situations should be provided for creating lovelyexperiences (Leonard, 1998, 82). These placesprovide conditions so that the people attend them and social relationships are formed with better quality.

\section{5-Natural space andsquares}

\section{5-1Natural space in the past and contemporary}

Human beings have been inspired by nature from the beginning of theirlife in various forms and this trend will continue for future generations. Man has always sought to enhance the quality in all spaces and using natural spaces in different forms and styles has always been useful. What is considered as nature in this study is use of elements such as water or green spaces which include trees and shrubs in the yard. Because we are part of nature, to become perfect human beings we have to be in contact with nature (Andrew Brennan cited by Bell, 2003, 119).

Relationship with nature is very important for a man regarding spiritual and material aspect and Islam hasfocused on this issue and emphasized oncontemplation about nature and natural events. Human being attaches importance to thinking innately and it is considered as one of most valuable worships in Islam. And environments withwhich humans are connected should be such that encourages people to draw their attention to the infinite universe.In the Islamic perspective,divine and innate intuition andknowledge can be achieved in nature and proximity to it. In this perspective interact with it in the man-made environments has been recommended a lot and facilitation of connection with nature has been the model for traditional architectures in building houses. This integration with quality, force and flow of different elements, circulation of spheres and continuous repetition of rhythm of light and dark that traditional Islamic architecture intensifies them and makes them obvious rather than hiding, is only for reminding Muslims about other revelation of God that is nature (Nasr, 2010, 69). In the past architecture,utilizing natural environment elements such as water, trees, greenery and light in semi-closed and open environments is seen. There has been 
use of nature in traditional houses of Iran, neighborhood centers, public spaces such as mosques, schools and caravanserais.

In contemporary architecture also, enjoying nature is embodied as various forms and this is seen from designing environmentally friendly urban furniture to using natural elements such as ponds and water fountains, streams, rocks and boulders, large and small rocks, grass, trees, flowers, bush and so on in contemporary urban squares ; that these elements with creative and appropriate design can be seen in important squares of the world. Hidalgo Plaza in Mexico City, Santa Ana Plaza in Spain and in Antrero Plaza inUruguay is examples of these fields.

According to Zucker, square is like amental stopplace in urban and local landscape where social interactionsof peoplehappen. At the same time, Zucker does not limit design of urbanspaces only to shape dimensions and visual beauty and focuses on social aspects and current activities in space strongly,(Zucker, 1970, 6). As stated,human activities and needs are not being limited to material needs and attention to the spiritual dimension is also very important.

Nature isan effective factor in human life avoids whichhas negativeand unpleasant impact on the human psyche. Our identity is associated with nature and the most basic step to preserve it is adherence to environmental ethics. It is not logical to recognize our direct benefitsfrom nature but do not care about its survival (Andrew Brennan cited by Bell, 2003: 119). Proper utilization of nature and natural elements have contributed to the survival and lasting of an environment and gives sense to man-made environments in the modern urban spaces. Such spaces act like a living space that today is as a pause point in the city for attendance of citizens.

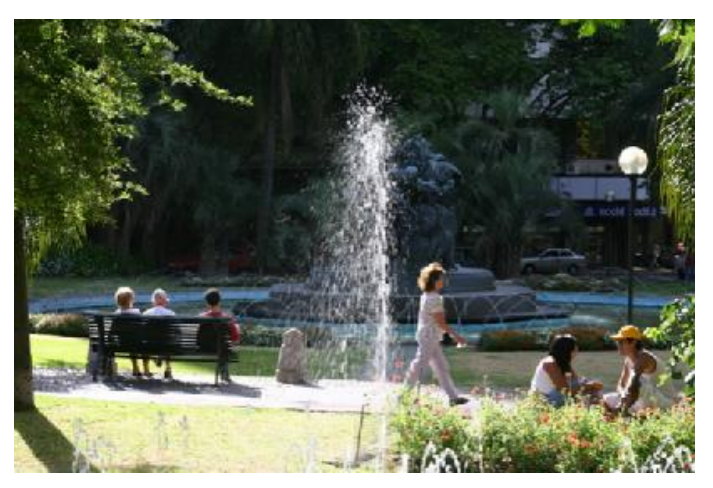

Fig.1. Presence of natural space in the Antrvrv plaza in Urugua. Source: http://www.pps.org 


\section{5-2 Purposes of using natural areas in square}

Squares arementioned as important urban spaceswhose quality is important in attracting citizens and optimal utilization of them. The use of natural space in squares ofmodern cities, whererole of nature in human life is reduced, has variety of purposes that a number of them are mentioned below.

1-Naturecausesense ofbelonging to place: many contemporary thinkers found sense of belonging to a place and maintaining nature and keeping harmony with itas indispensable to each other. Theorists such as Chon (Chermayeff) and (Alexander),have discussed the vacuum left by the absence of nature frommodern man's life. They describe sincere connection of human with nature as unique (Chermayeff and Alexander, 1353, 48). Natural spaces have important impact on feelingsof users and their aesthetic understanding and can increase their positive emotions, comfort and belongingness towards the environment. Having close relationship with nature has impact on mental growth and development individuals (Hafezian, 2006, 78). Creation of positive feelings and peace of mind cause users sense of belonging to the environment and hence more understanding of place, sense of place and belonging to done living environment and society is achieved.Sense of belonging to place that is made by sense of place causes human to consider himself part of the placeand based on his experience of signs, meanings and performances, assume a character and role for place in mind and thus the place gets important and respectable to him (Falahat, 2006, 60).

2-Creating a favorable environment for users: Using natural spaces such as shading trees and benefiting elementslike water and air jets to modifyair and creating apleasant space in most climates in Iran is very useful. Natural space creates a favorable environment for users in squares and brings an opportunity in which many meetings and leisure happen during daylight hours for short-term or even a few hours.

3-The nature and its elements such as trees and water have been very valuable in Iranian culture and have semantic aspects in addition their functional aspect. In Islam also reflecting on the nature is recommended. Religious vision that originates from Islamic verses and traditions, recommends humans to benefiting and at the same time construction in nature and in line with spiritual attentions, considers interaction with nature and contemplation in natural actions, other than material efficiency, cause of spiritual growth, understanding power of God and a obtaining worship spirit(Dai Poor, 2014, 51). 


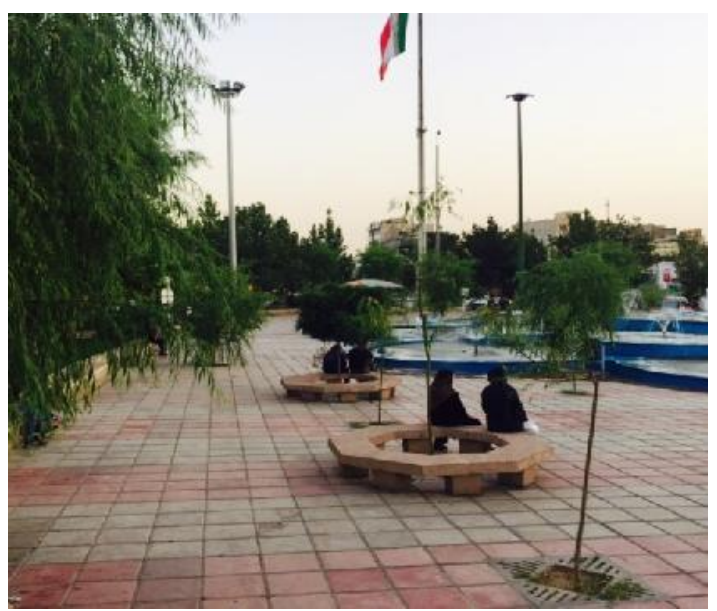

Fig.2. Presence of natural elements in The First Circle of Tehranpars Source: the authors.

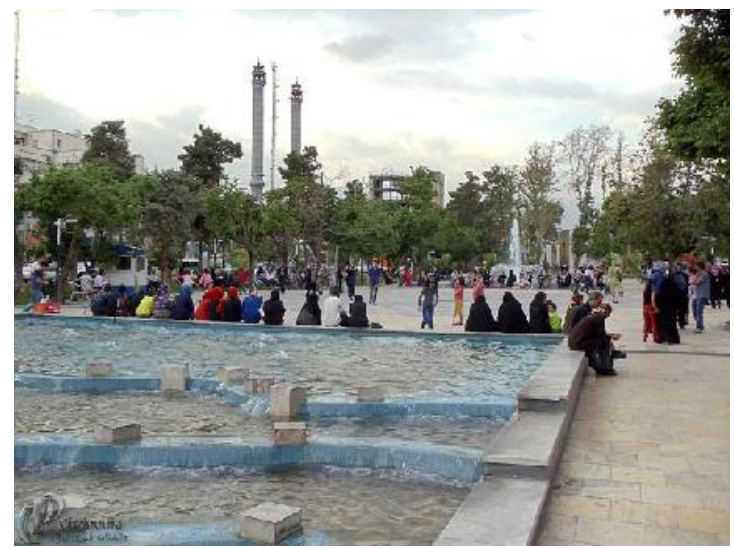

Fig.3. Presence of natural elements in Haft-Hoz, Tehran. Source: The authors

\section{6- DISCUSSION}

People and activities they do in a city are like mobile agents that are effective in creating a mental image of the city. Building natural spaces around the square, in addition to highlighting presence of people, makes the image and face of the city more beautiful.

In this study 6 squares in Tehran werestudiedthat for evaluating them 10 specialists in the field completed the questionnaire. The aim of this study, as mentioned, was to investigate the relationship between vitality and sociability in urban squares and the use of natural space in them. In this regard, the natural space is considered as an independent factor toevaluate its impact on the vitality and sociability. The study has been conductedbycorrelation research method through questionnaires and finally the data has been analyzed using SPSS software.

Regression coefficients extracted are used indetermining the relationship between agents and their exactratio. The coefficients were determined from the regression determining tables, a sample of which is brought in the tables. Correlationtable can be used to determine the 
relationship between the agents. The table determines the direct or inverse relationship between the agents and their numerical impact on each other.

Natural space is independent variable, and vitality and sociability are dependent variables. After performing the calculations, it was shown that the agent nature, vitality and sociability have a direct relationship with each other; in other words, natural space and vitality and sociability affected each other and given the positive correlation coefficient this relationship is direct, that is increasing natural green space increases these two factors (table 1). Also the vitality and sociability factors have direct relationship; in other words, vitality and sociability affect each other and given the positive correlation coefficient this is a direct relationship, that is increased sociability enhances vitality (table 2).

Table 1. Extracted regression coefficients, source: the authors

\begin{tabular}{|c|c|c|c|c|c|c|}
\hline \multicolumn{7}{|c|}{ Extracted regression coefficients } \\
\hline & \multirow[t]{2}{*}{ Sample } & \multicolumn{2}{|c|}{$\begin{array}{l}\text { unstandardized } \\
\text { regression } \\
\text { coefficients }\end{array}$} & \multirow{2}{*}{$\begin{array}{l}\text { standardized } \\
\text { regression } \\
\text { coefficients } \\
\text { Beta }\end{array}$} & \multirow[t]{2}{*}{$\begin{array}{c}\mathrm{t}- \\
\text { statistic }\end{array}$} & \multirow[t]{2}{*}{$\begin{array}{c}\text { Significance } \\
\text { level }\end{array}$} \\
\hline & & B & Std.Error & & & \\
\hline \multirow{3}{*}{1} & (Dependent) & .425 & .200 & & 2.123 & .038 \\
\hline & Sociability & .451 & .087 & .527 & 5.202 & .000 \\
\hline & Vitality & .371 & .092 & .410 & 4.045 & .000 \\
\hline \multicolumn{4}{|c|}{ ndependent variable: natural space } & & & \\
\hline
\end{tabular}


Table 2. Correlation coefficient, source: the authors

\begin{tabular}{|c|c|c|c|c|}
\hline \multicolumn{5}{|c|}{ correlation coefficient } \\
\hline & & & Sociability & Vitality \\
\hline \multirow[t]{6}{*}{ Spearman's rho } & \multirow[t]{3}{*}{ Sociability } & correlation coefficient & 1.000 & $.768 * *$ \\
\hline & & Significance level & . & .000 \\
\hline & & number & 60 & 60 \\
\hline & \multirow[t]{3}{*}{ vitality } & correlation coefficient & $.768 * *$ & 1.000 \\
\hline & & Significance level & .000 & . \\
\hline & & number & 60 & 60 \\
\hline \multicolumn{3}{|c|}{ **. Correlation is significant at the 0.01 level (2-tailed). } & & \\
\hline
\end{tabular}

This test demonstrates that sociability and vitality affect each other community and given positive Spearman correlation coefficient $=0.768 * *$, this is direct relationship, that is increased sociability enhances vitality and the reverse is also true (Table 2).

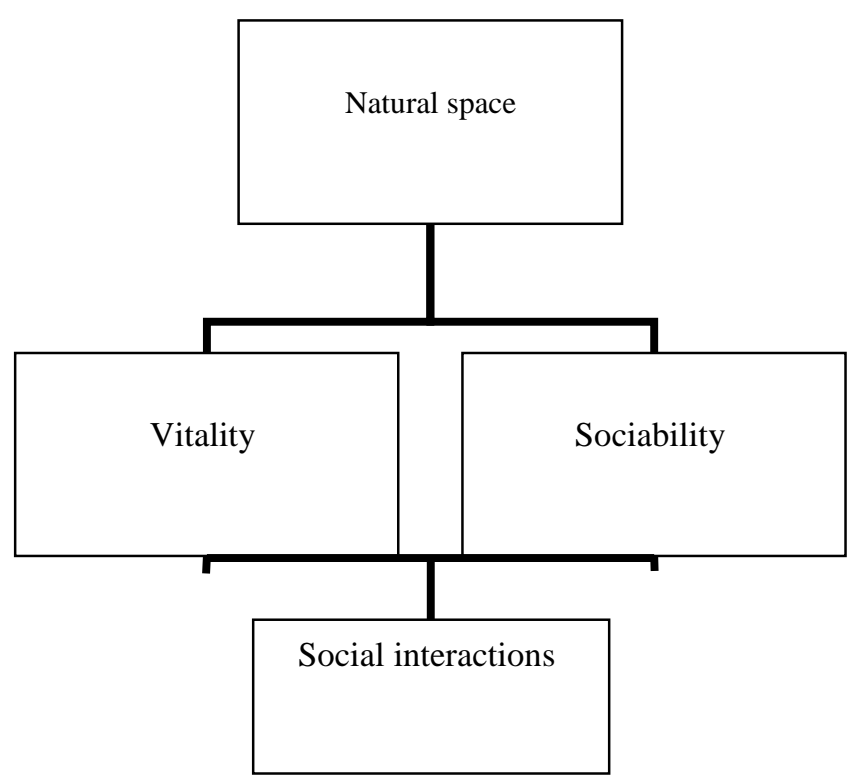

Fig.2. The relationship between natural space, sociability, vitality and social interactions (Source: drawn by the authors) 


\section{7 .CONCLUSION}

In order to approach an ideal and appropriate city, urban spaces that enhance social interaction and solidarity among human beings are needed. Architecture and urban development should take an important step forward to the link between people and public spaces such as squares that are as suitable context for social interaction. One of the most important measures to enhance the quality of urban space is integration of these environments with the natural environment and the use of multiple potentials of the nature. Presence of green space, water and the nature besides living spaces has been common from the old times in old neighborhoodsand at the present time cities are formed according to this new scale.

This study shows that factors such as vitality and sociability play an important role in social interactions that increasein eachcauses increase in social interactions and thus improves knowledge of society. On the other hand the use of natural space increases vitality and sociability that ultimately increase social interactions:

The study also found that sociability and vitality affect each other and have a direct relationship; and increasesin each of these factors cause increases in the other one. Today human has ignored using nature and its elements in many areas of social and individual life; this is while enjoying nature can be fruitful in all areas especially in modern urban spaces where man's natural needs have been paid attention to less.

\section{REFERENCES}

1-Bell, Simon, landscape, pattern, perception and process. T: Behnaz Amin Zadeh. Tehran: Tehran University, 2003.

2-Bemanian, Mohammad R, Pourjafar, Mohammad R, Ahmadi, Ferial, Sadeghi, Ali R. Rereading spiritual identity and sacred notionsin architectureof Shiite mosques, Shia Studies Quarterly, Issue 30, Qom, pp. 70-37, 2010

3-Parsi, H. R. Recognizing the content of urban space fine arts, Issue 11, pp. 49-41, 2002.

4-Pakzad, J, qualitative criteria to measure the space. Abadi, No. 39, 2003.

5-Pour M, Mohammad R, Kushaneh R.Analysis and evaluation of urban public spaces using TOPSIS model (Case Study: Tabriz), urban and regional studies, No. XVII, page 37-52,2013. 6-Chermayeff, Search and Alexandre, Christopher, 1353 .The areas of private life and public life. Complied by : Manuchehr Mazini. Tehran: Tehran University.

7-Hafezian,T. Green space, School magazine, ,2006, No. 41, Tehran. 
8-Khastu, M, Saeedi R, N, factors affecting the vitality of urban spaces to create a lively urban space based on the concept of on foot shopping center, Journal of city identity, Issue 6, 2010, page 63-74.

9-Falahat, M S. The concept of sense of place, and factors shaping it. Journal of Fine Arts, 2006, Issue 26, 57-66.

10- Fielding A W and Nimkaf, M F. Sociology background, translated by Amir Hossein Aryanpur, martyr Beheshti University Press, Thirteenth Edition, 1380.

11-Dai pour, Z, The relationship between presence of nature and increase of sense of belonging in a traditional houses of Iran. Bagnazar Quarterly, 2014, Issue 30, Volume XI.

12-Rafipour, F. Anatomy of Society: An Introduction to Sociology, Applied. Tehran: Publication Corporation, 2003.

13-Saif, A A, educational psychology (teaching and learning), Tehran, Aghah publications, 2007.

14- Krohercent, L, Suz A and Henry L, "designing urban space and social life", translated by Rasoul Mojtabapour. Architecture and Urban Development, Seventh period,Number 44 and 45, 1998.

15- Madanipour, A, urban public and private spaces, Farshad Nourian. Urbanprocessing andplanning company, Tehran, 2008.

16-Nasr, S H, Islamic art and spirituality. Tehran: Hekmat Publications, 2010.

17-Aksoy, P, Baran, G Review of studies aimed at bringing social skills for children in preschool period. Procardia social and Behavioral sciences, 2010: 663_669.

18-Smond H, Function as the Basis of Psychiatric Ward Design. New York. Holt Rinehart and Winston, 1957.

19-Hajer, M and Reijndorp, A; 'In Search of New Public Domain'; Rotterdam; NAi Publishers, p.11, 2001.

20-Zucker, P (1970), "Town and Square; from the agora to the village Green", The MIT Press,http://www.pps.org/reference/internationalsquares/

\section{How to cite this article:}

Saremi R H, Ghasemi Z, Bemanian R M, Sattarpour M. The effect of nature on social interactions in urban squares (case study: squares of tehran). J. Fundam. Appl. Sci., 2016, $8(2 S), 1765-1776$. 